\title{
Removal of chlorhexidine digluconate from aqueous solution by heterogenous photocatalysis using sunlight-driven Ni-doped $\mathrm{TiO}_{2}$ material
}

\author{
Astha Singh, Brijesh Kumar Mishra ${ }^{\dagger}$ \\ Department of Environmental Science and Engineering, Indian Institute of Technology (Indian School of Mines), Dhanbad-826004, India
}

Received November 02, 2021 Revised December 10, 2021 Accepted January 03, 2022

\begin{abstract}
Photoactive $\mathrm{Ni}_{-} \mathrm{TiO}_{2}$ was synthesized through green hydrothermal method with preferential photocatalytic performance in visible and solar light for synthetic and formulated wastewater treatment. Incorporation of this transition metal into $\mathrm{TiO}_{2}$ was examined by XRD, FTIR, UV-visible DRS, XPS, SEM-EDS and HRTEM analysis. According to the Langmuir-Hinshelwood model, the photodegradation of the chlorhexidine digluconate under solar $\left(R^{2}=0.986\right)$ and simulated visible light $\left(R^{2}=0.982\right)$, follows a pseudo-first-order kinetics. The interaction of operational fractions, such as $\mathrm{S} / \mathrm{C}$ ratio, irradiation time, and $\mathrm{pH}$ of the reaction mixture, were evaluated using the RSM. Although complete mineralization of $\mathrm{CHD}$ was not achieved using $\mathrm{Ni}^{-\mathrm{TiO}_{2}}$ under visible light, but the parent compound was mineralized to some extent, as demonstrated by TOC reduction (85.71\%-synthetic wastewater and $61.17 \%$-formulated wastewater), $\mathrm{UV}_{254}(89.91 \%$ synthetic wastewater and $55.39 \%$-formulated wastewater) and $\mathrm{UV}_{280}(68.23 \%$-synthetic wastewater and $68.23 \%$-formulated wastewater) absorbance variations. Based on the identified transformed products, the possible degradation pathway was proposed and bacterial susceptibility test on Bacillus cereus DPAML065 was performed to evaluate the toxicity of oxidation intermediates. Comparative studies about energy consumption and removal efficiency during simulated visible light/Ni-TiO $\mathrm{O}_{2}$ and sunlight/ $\mathrm{Ni}-\mathrm{TiO}_{2}$ mediated treatment system for formulated wastewater revealed that sunlight/ $\mathrm{Ni}-\mathrm{TiO}_{2}$ mediated treatment system was high energy efficient $\left(1.67 \mathrm{kWhKg}^{-1}\right)$ system.
\end{abstract}

Keywords: Formulated wastewater, $\mathrm{Ni}$-doped $\mathrm{TiO}_{2}$ catalyst, Power consumption, Solar photocatalysis

\section{Introduction}

Although personal care products (PCPs) have been used for decades, their fate and discharge into the aquatic environment only has recently been identified as one of the most significant environmental chemistry issues. In accordance with the Water Framework Directive (2000/60/EC of the European Parliament and Council) and other legal statutes (Decision 2455/2001/EC, Directive 2008/105/EC), various organic pollutants including PCPs have been identified as priority pollutants in the environmental strategy of EU against water pollution [1]. These compounds are formulated to be physiologically active and resistant to biodegradation, which significantly increases their presence in aquatic environment and are labelled as "pollutant" [2]. The principal pathway of these compound into the aquatic ecosystem is through excreta from human or animal urine or faces [3]. The model compound chlorhexidine digluconate (CHD) is widely used as a disinfectant in handwash, sanitizer, toothpaste, mouthwash, and cosmetic preservatives. When the COVID-19 pandemic broke out, the use of personal care products such as disinfectants soared dramatically in hospitals, health care facilities, and households all around the world [4]. They are excreted directly into the environment after usage, without being modified or treated in any way. The long-term exposure of CHD is associated with harmful effect on human health. Even though small concentration of $\mathrm{CHD}$ has received little attention because it was found that transformed products render the total mineralization of parent compound. Additionally, monitoring programs of the European Union for pharmaceutical and personal
This is an Open Access article distributed under the terms of the Creative Commons Attribution Non-Commercial License (http://creativecommons.org/licenses/by-nc/3.0/) which permits unrestricted non-commercial use, distribution, and reproduction in any medium, provided the original work is properly cited.

Copyright (C) 2023 Korean Society of Environmental Engineers
${ }^{\dagger}$ Corresponding author

E-mail: brijesh@iitism.ac.in

Tel: +91-326-2235752

Fax: +91-326-2296624

ORCID: 0000-0002-4451-1924 
care products are not yet defined even though they could be future candidates for causing acute or chronic toxicity in the aquatic ecosystem [5].

Thus, removal of CHD is not adequate effective by conventional treatment process. Therefore, considering the disadvantages of all the conventional treatment, semiconductor nanostructure developed significantly in the field of photocatalytic application for efficient removal of organic pollutant [6]. High quantum efficiency, high chemical stability in aqueous media, inexpensiveness, and nontoxicity of $\mathrm{TiO}_{2}$ were recognized as a significant reason for their widespread acceptance as photocatalyst compared to another semiconductor. Nevertheless, some of their internal limitations including poor visible light consumption, decreased photogenerated electrons and holes pairs separation, and a lack of active species generation hampered their practical uses. Thus, the development of an efficient and new type visible light-driven (VLD) photocatalysts, as well as extensive synthesis and modification methods, are the main challenges in current studies to maximize the exploration of solar light [7, 8].

Very recently, transition metal/nonmetals (V, Cr, Mn, Fe, Ni, $\mathrm{Cu}$ ) doped $\mathrm{TiO}_{2}$ are widely used photocatalysts for the removal of organic pollutant. In addition to this, wide band gap, high oxidation capacity, low cost, and remarkable potential application under visible and solar radiation of $\mathrm{Ni}$ doped $\mathrm{TiO}_{2}$ have been found to be promising photocatalyst [9]. To obtain the sunlight driven photocatalyst, the addition of Ni-content tuned the band gap from 3.03 to $2.54 \mathrm{eV}$ for tetragonal and cubic structure of $\mathrm{TiO}_{2}$ and $\mathrm{Ni}^{-T i O}{ }_{2}$, respectively. Furthermore, similar ionic radius of $\mathrm{Ti}^{4+}\left(0.68{ }^{\circ} \mathrm{A}\right)$ and $\mathrm{Ni}^{2+}\left(0.72{ }^{\circ} \mathrm{A}\right)$, could be beneficial in the substitution of $\mathrm{Ni}^{2+}$ in the place of $\mathrm{Ti}^{4+}$ in the crystalline lattice of $\mathrm{TiO}_{2}$ [10]. Though various studies reported the modification of electrical and optical properties by controlling their microstructure for practical applicability [11]. The development of a simple and cost-effective method for producing high-yield nanostructured $\mathrm{Ni}-\mathrm{TiO}_{2}$ toward sunlight driven photocatalytic application remains a major challenge.

Photodegradation involves number of independent and dependent variables because this manual optimization is quite difficult to carry out. Keeping the above facts, Response surface methodology (RSM) has been used to elaborate the interaction among the operating condition ( $\mathrm{pH}$, substrate to catalyst ratio and time) and their subsequent effect on photocatalytic activity with respect to mineralization of $\mathrm{CHD}$, phenolic compound, and reduction of aromaticity during photocatalysis process [12]. The optimization of photocatalysis process has been carried out using Face Centered Central Composite Design (FCCD), resulting in a good estimate of the optimum response.

To understand the mineralization process of PCPs such as CHD into their transformed products and conversion of heteroatoms as well as functional group during photocatalysis process are again another challenging task. Monitoring of such intermediate generally carried out with the help of GC-MS, LC-MS and HPLC, which is the time consuming and costly procedural. The present study not only provide ideal scenario for photocatalysis process with different photocatalyst, but also opens a new avenue to understand the mineralisation of emerging pollutant coupled with simultaneous reduction of phenolic as well as aromaticity through Absorbance Slope Index (ASI) and spectral indices [13]. For example, UV absorbance at specific wavelengths (e.g., UVA 203, 204, 220, 230, 253 254, 260, 265, 272, 275 and 280), and ASI correlate well with the degradation $\mathrm{CHD}$, aromaticity, hydrophobicity and transformed products. In previous studies, employment of spectral indices approach for characterization of DOM (aromatic components) has been demonstrated to be feasible, fast and easy tool [14].

In this research, a green hydrothermal synthesis approach was adopted, which is simple to use and can reduce time as compared to other conventional $\mathrm{TiO}_{2}$ modification techniques. The work describes the effect of Ni-doping on the photocatalytic activities of $\mathrm{TiO}_{2}$ under natural sunlight and simulated visible light with respect to degradation of the $\mathrm{CHD}$, the mineralization rate (in terms of TOC) and UV absorbance ( $\mathrm{UV}_{254}$ and $\left.\mathrm{UV}_{280}\right)$. Meanwhile, the presence of Ni-particle in $\mathrm{TiO}_{2}$ was validated by XPS, XRD, HRTEM and EDS. Radicals trapping experiment carried out to discuss the prominent radicals in the photodegradation system. A toxicity test of oxidation intermediates, high reusability, and electrical energy consumption, indicating the practical reliability and safe disposal of $\mathrm{Ni}^{-}-\mathrm{TiO}_{2}$. The research also established the efficiency of photo mineralisation of CHD through HPLC and toxicity test of its oxidative by-products on the water bodies. Thus, current study provides the guidance for large scale applicability of $\mathrm{Ni}^{-\mathrm{TiO}_{2}}$ system in the field of pharmaceuticals and personal care products (PPCPs) with special emphasis on personal care products loaded wastewater.

\section{Materials and Methods}

\subsection{Materials}

Chlorhexidine digluconate (CAS \# 18472-51-0-C9394) of 20\% in $\mathrm{H}_{2} \mathrm{O}$ was purchased from Sigma-Aldrich. Titanium dioxide and other chemicals were procured from Merck (India) and Sigma-Aldrich. Chlorhexidine digluconate solution and formulated wastewater were prepared using a Milli-Q water system (Millipore). All chemicals are analytical graded.

\subsection{Synthesis of Photocatalyst}

The raw material and precursor used for preparation of Ni-doped $\mathrm{TiO}_{2}$ includes titanium tetra-isopropoxide, $\mathrm{Ni}\left(\mathrm{NO}_{3}\right)_{2} \cdot 6 \mathrm{H}_{2} \mathrm{O}$ and $\mathrm{HNO}_{3}$. The clear aqueous solution was prepared by adding 10 $\mathrm{mL}$ of titanium tetra-isopropoxide into a beaker containing 60 $\mathrm{mL}$ of deionized water and $10 \mathrm{~mL}$ of isopropanol for $1 \mathrm{~h}$ of stirring. This clear solution was then added to $3 \mathrm{mmol}$ of nickel (II) nitrate hexahydrate and $60 \mathrm{~mL}$ of $0.02 \mathrm{M}$ nitric acid for 2 $\mathrm{h}$ of continuous stirring. After obtaining clear solution, later add ammonium hydroxide drop-wise into the solution followed by vigorous stirring for $2 \mathrm{~h}$ to obtain a residue. The stirring was maintained for the next $6 \mathrm{~h}$ at a steady temperature of $80^{\circ} \mathrm{C}$ to ensure proper mixing of the solution. The resulting material was washed several times using distilled water to remove the impurities and dried in the air for $24 \mathrm{~h}$. Thus, dried material was grinded in agate mortar and then calcined in the furnace at $6000^{\circ}$ for $2 \mathrm{~h}[10,15]$. 


\subsection{Characterization of Photocatalyst}

The crystallinity, morphology, elemental analysis, optical measurement, and bandgap modification of the prepared photocatalyst were analyzed. Scanning electron microscopy (SEM) using Hitachi S-4300 type, High Resolution Transmission electron microscopy (HRTEM), energy dispersive spectroscopy (EDS) and selected area electron diffraction (SAED) patterns were used to examine the morphology, microstructure, distribution, and incorporation of elements on the $\mathrm{TiO}_{2}$. X-ray diffraction (XRD) were recorded using $\mathrm{Cu}-\mathrm{K} \alpha(\lambda=1.5406 \AA)$ radiation on a Bruker D8 ADVANCE diffractometer to analyze the crystalline phase of the prepared material. The optical properties of the sample were recorded from UV-vis spectrophotometer (Perkin Elmer Lambda 900 spectrophotometer) equipped with $\mathrm{BaSO}_{4}$ powder was used as a reference for baseline study. Bandgap calculated from the modified Kubelka- Munk plot against wavelength ranging from $200-900 \mathrm{~nm}$ using diffuse reflectance spectra (DRS). The Brunauer Emmett Teller (BET) model was used to calculate specific surface area using the linear portion $(\mathrm{P} / \mathrm{Po}=0.05-0.2)$. The infrared spectrum of $\mathrm{Ni}-\mathrm{TiO}_{2}$ was scanned through Bruker Vertex- 70 Fourier transform infrared (FTIR) to identify the presence of functional groups of prepared material. X-ray photoelectron spectroscopy (XPS) were used to examine the oxidation state and charge compensation of the element present in the material using a VG 250 Escalab spectrometer equipped with an $\mathrm{Al}$ anode $(\mathrm{Al}-\mathrm{K} \alpha=1,486.7 \mathrm{eV})$ as an X-ray source. The textural and optical properties of the synthesized catalysts are given in Table S1.

\subsection{Synthetic Wastewater Formulation}

The pharmaceutical wastewater was prepared in the laboratory, based on the composition of real wastewater of the pharmaceutical industry with slight modifications [16]. The physiochemical characteristics of formulated wastewater such as $\mathrm{pH}$, TOC, COD, $\mathrm{BOD}_{5}$ and Ultraviolet (UV) absorbance at $254 \mathrm{~nm}$ are presented in Table S2.

\subsection{Experimental Setup and Procedures}

The photocatalytic activity of $\mathrm{Ni}-\mathrm{TiO}_{2}$ was investigated through $\mathrm{CHD}$ degradation using simulated visible light and natural sunlight as a source of irradiation. In a typical photocatalytic degradation experiment using simulated visible light, an aqueous solution of $\mathrm{CHD}$ was mixed and stirred well with $\mathrm{Ni}^{-\mathrm{TiO}_{2}}$ powder in a photocatalytic system consisting of a $1 \mathrm{~L}$ Pyrex reactor (diameter 96 $\mathrm{mm}$ and height $140 \mathrm{~mm}$ ) with Hg lamp (200 W), mounted inside the system and a beaker with the same dimensions used for sunlight mediated experiment. To compare the performance of $\mathrm{Ni}^{-\mathrm{TiO}_{2}}$ in different light sources, the photocatalytic degradation of formulated wastewater containing $\mathrm{CHD}$ was also carried out using UV, visible, and solar light as irradiation sources [17]. The suspension was sonicated for $5 \mathrm{~m}$ and then irradiated with simulated visible light (300-420 nm and $40 \mathrm{~m} \cdot \mathrm{W} / \mathrm{cm}^{2}$ ) or sunlight $\left(30-40 \mathrm{~m} \cdot \mathrm{W} / \mathrm{cm}^{2}\right)$. The light intensity was measured by a radiometer (Delta OHM, LP-NET14). Aliquots (3 $\mathrm{mL})$ were taken from the suspension at equal intervals, and centrifuged $\left(4^{\circ} \mathrm{C}, 11,000 \mathrm{X} \mathrm{g}, 5 \mathrm{~min}\right)$ before being filtered with $0.22 \mathrm{~m}$ syringe filters for UV absorption spectra and TOC analyses.

\subsection{Experimental Design Using Response Surface Methodology}

Response Surface methodology was used to optimize three variables ( $\mathrm{S} / \mathrm{C}$ ratio, $\mathrm{pH}$ and time) with 3 different levels $(+1,0$ and -1$)$ for maximum $\mathrm{CHD}$ removal as response. The experiment design (DoE) was performed on the basis of the FCCD devised by Design Expert v7.0.0 software (SaMeep 104, State Ease, INC. Minneapolia (USA). A total of 20 different combinations were obtained with six center points in random order according to Central Composite Design (CCD) configuration for three factors. In this analysis, FCCD was used to model the percentage removal of $\mathrm{CHD}$ as quadratic model. Statistical validation was done by using "Analysis of variance" (ANOVA), correlation coefficient $\left(\mathrm{R}^{2}\right)$, lack of fit, CV\% and

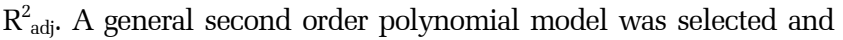
expressed by an Eq. (1) to investigate the effects of individual parameters as well as their synergistic interactive effects on the response variable [12].

$$
y=b_{o}+\sum_{i=1}^{3} b_{i} X_{i}+\sum_{i=1}^{3} b_{i i} X_{i}^{2}+\sum_{j=1}^{3} \sum_{j=1}^{3} b_{i j} X_{i} X_{j}
$$

Where $y$ is the response variable, $b_{o}$ is the constant, $b_{i}$ the linear coefficient, $b_{i i}$ the quadratic coefficient, $b_{i j}$ the interaction coefficient and $X_{i}$ dimensional coded variables (X1 for the S/C ratio, X2 for the time and $\mathrm{X} 3$ for the reaction medium $\mathrm{pH}$ ).

\subsection{Analytical Procedure}

The quantitative measurements of concentration of CHD and their degradation products were monitored by UV-vis spectrophotometer (Lab-tech, China) at $275 \mathrm{~nm}$ wavelength and LC-MS analysis (Thermo Scientific TSQ 8000 liquid chromatograph-mass spectrometer). TOC analyser (Shimandzu 5000) was used to determine the extent of $\mathrm{CHD}$ mineralization.

The Langmuir-Hinshelwood model has been carried out to study the modelling CHD degradation Eqs. (2) and (3).

$$
\begin{gathered}
\ln \frac{C_{t}}{C_{o}}=-k_{o b s} t \\
r_{o b s}=-k_{o b s} C_{C H D}
\end{gathered}
$$

Where, $k_{o b s}$ (Reaction rate constant) was calculated from the slope by plotting a graph between $\ln \frac{C_{t}}{C_{o}}$ versus $\mathrm{t}$ and $r_{o b s}$ is the observed $\mathrm{CHD}$ degradation rate $\left(\mathrm{mg} \mathrm{L}^{-1} \mathrm{~min}\right)$ in the photoreactor [18].

UV absorbance at various wavelengths (203, 204, 220, 230, 253 254, 260, 265, 272, 275 and 280) were employed to investigate the reduction in aromaticity of compound, residuals of phenols and ASI, calculation can be represented as [19]:

$$
A S I=0.56\left[\frac{A_{254}-A_{272}}{A_{220}-A_{230}}\right]
$$

Where $A_{220}, A_{230}, A_{254}$ and $A_{272}$ are the representative of UV absorbance at wavelength 220, 230, 254 and $272 \mathrm{~nm}$, respectively.

The quantitative measurements of the conversions of $\mathrm{CHD}$ and 
the degradation products were validated on a High-Performance Liquid chromatograph (Phenomenex UK) equipped with a hyperclone (Eclipse plus C18 column; $3.5 \times 4.6 \times 100 \mathrm{~mm}$ ) and connected to a UV-ViS detector. The spectrophotometer was set at $275 \mathrm{~nm}$ and $1.5 \mathrm{ml} / \mathrm{mi}$. flow rate for $10 \mathrm{~min}$. of retention time was used for the chromatograph. As a mobile phase solution of acetonitrile $(70 \% \mathrm{v} / \mathrm{v})$ and ultrapure water $(30 \% \mathrm{v} / \mathrm{v})$ was selected. Sample injection volumes were $10 \mu \mathrm{L}$ and filtered by $0.2 \mu \mathrm{m}$ syringe filters prior to injection [5]. Liquid Chromatography-Mass Spectrophotometer was used to investigate degradation pathway of $\mathrm{CHD}$ and its metabolites formation.

\subsection{Bacterial Susceptibility Test}

Bacillus cereus DPAML065 was used in a susceptibility test to determine the toxicity of partially/fully mineralized CHD using autoclaved Muller Hinton agar medium and petri plates at $121^{\circ} \mathrm{C}$ for $20 \mathrm{~min}$. Approximately $1 \mathrm{~mL}$ of Bacillus cereus culture broth suspension was added to fresh medium and mixed. After incubation, this homogeneously mixed culture solution of bacteria and medium displays a confluent lawn of growth. Prior to the observation of the inhibition zone, the bacterial growth was incubated for $24 \mathrm{~h}$ at $37^{\circ} \mathrm{C}$.

\section{Results and Discussion}

\subsection{Characterization of the Photocatalysts}

The XRD pattern showed the phase structure of the prepared photocatalyst in (Fig. 1(a)). The observed peaks at $\sim 25^{\circ}$ and $56^{\circ}$ confirm the anatase form of tetragonal structure of pure $\mathrm{TiO}_{2}$ matched with (ICSD reference number 01-086-1155). In addition, the characteristic peaks of $\mathrm{NiTiO}_{3}$ at $\sim 27^{\circ}, 36^{\circ}, 47^{\circ}$ and $54^{\circ}$ were ascribed the cubic structure of $\mathrm{Ni}-\mathrm{TiO}_{2}$ matched with (ICSD reference number 01-075-0399) [20]. Thus, analysis provides a possible assumption that incorporation of $\mathrm{Ni}^{2+}$ into the $\mathrm{TiO}_{2}$ favouring the formation of $\mathrm{NiTiO}_{3}$ [21]. The intensity of peaks of undoped $\mathrm{TiO}_{2}$ decreased and slightly shifted due to the doping of metal; this revealed that $\mathrm{Ni}$ enter the $\mathrm{TiO}_{2}$ crystal lattice successfully. This $\mathrm{Ni}^{2+}$ could replace $\mathrm{Ti}^{4+}$ due to the similar ionic radius i.e. $0.72 \mathrm{~A}^{0}\left(\mathrm{Ni}^{2+}\right)$ and $0.68 \mathrm{~A}^{0}\left(\mathrm{Ti}^{4+}\right)$ and cause distortion as well as a defect in their lattice. Cubic crystal structure of $\mathrm{Ni}-\mathrm{TiO}_{2}$ demonstrated that doping of nickel modifies the tetragonal crystal structure of $\mathrm{TiO}_{2}$ and $\mathrm{Ti}^{4+}$ lattice sites were occupied by $\mathrm{Ni}^{2+}$ as a substitutional impurity [11]. This phase transformation was observed with incorporation of $\mathrm{Ni}$ content can be explained by the fact that when $\mathrm{Ni}$ and $\mathrm{Ti}$ bond attached to $\mathrm{O}$ atom, Ti loses electron more easily than $\mathrm{Ni}$ atom due to the difference of electronegativity between $\mathrm{Ti}$ (1.54) and Ni (1.91). Thus, the large angle was found between the among $\mathrm{Ni}-\mathrm{O}$ bonds than the $\mathrm{Ti}-\mathrm{O}$ bonds this leads to the stronger interaction between the second $\mathrm{Ti}-\mathrm{O}$ bonds and also due to the stronger polarity of the $\mathrm{Ni}-\mathrm{O}$ bonds and hence results in deviation of crystal structure from tetragonal to cubic [22]. The Debye-Scherrer formula used FWHM data form the XRD peak to calculate the average crystallite sizes of the photocatalyst (Eq. (5)).

$$
D=\frac{K \lambda}{\beta \cos \theta}
$$

Moreover, it was found that there is decrease in crystallite size of pure $\mathrm{TiO}_{2}(3.91 \mathrm{~nm})$ due to doping of nickel in $\mathrm{Ni}-\mathrm{TiO}_{2}(2.96$ $\mathrm{nm})$. Thus, $\mathrm{Ni}^{2+}$ tries to replace $\mathrm{Ti}^{4+}$ which may be better explained by the broadening of peaks due to defects formed by $\mathrm{Ni}^{2+}$ in $\mathrm{TiO}_{2}$ [23]. Fig. 1(b) depicts clearly the prominent peak and shifting of $2 \theta$ in prepared material $\left(\mathrm{Ni}-\mathrm{TiO}_{2}\right)$, which verifies the doping of $\mathrm{Ni}$ in $\mathrm{TiO}_{2}$ [24]. Doping of $\mathrm{Ni}^{2+}$ in $\mathrm{TiO}_{2}$ inhibits the size of crystallite and enhance the formation of anatase crystalline phase of $\mathrm{TiO}_{2}$. This smaller crystallite size of $\mathrm{Ni}^{-\mathrm{TiO}_{2}}$ particles were further validated by the scanning electron microscopy (SEM) and our findings are consistent with previous studies [10].

The SEM and High-resolution transmission electron microscopy (HRTEM) confirmed the smaller crystallite sizes of Ni-doped $\mathrm{TiO}_{2}$ particles. The SEM micrographs of undoped $\mathrm{TiO}_{2}$ clearly shows the uniform regular spherical particle distribution (Fig. 2(a), (b)). After loading of Ni, the surface of $\mathrm{TiO}_{2}$ sphere exhibits both spherical and slightly elongated rod-like porous structure (Fig. 2(c) (h)). Furthermore, EDS analysis was also performed to verify and confirm the elemental composition of undoped $\mathrm{TiO}_{2}$ and the loading of $\mathrm{Ni}$ content in $\mathrm{Ni}-\mathrm{TiO}_{2}$. The EDS spectrum shows the presence of $\mathrm{Ti}, \mathrm{O}$ along with $\mathrm{Ni}$ were found confirming the undoped and $\mathrm{Ni}$ doped $\mathrm{TiO}_{2}$ [10]. The content of observed element in sample are mentioned in Table S1. HRTEM images and selected area electron diffraction (SAED) patterns show the presence of the lattice fringes and crystallinity of prepared material. Additionally, mapping shows the successful incorporation and equal distribution of metal ion onto $\mathrm{Ni}^{-\mathrm{TiO}_{2}}$ sample [25].

FTIR spectrum was recorded to elucidate the presence of chemical group on the surface of $\mathrm{TiO}_{2}$ and formation $\mathrm{Ni}^{-T i O}$ (Fig. 1(d)). The broad hump on $\mathrm{TiO}_{2}$ and $\mathrm{Ni}-\mathrm{TiO}_{2}$ showed absorption peak around 3,402.71 $\mathrm{cm}^{-1}$, which is characteristic peak of the $\mathrm{OH}$-stretching vibration of surface absorbed water molecules. The peak representing Ti-O stretching bond were identified at $544 \mathrm{~cm}^{-1}$, which is the characteristic band of pure $\mathrm{TiO}_{2}$ sample [26]. Interestingly, characteristic peak of metal-oxygen vibrational bond were observed in the range of 700-400 $\mathrm{cm}^{-1}$, thus sharp absorption peaks around $500-450 \mathrm{~cm}^{-1}$ confirms the characteristic peak of metal titanate bond $\mathrm{Ti}-\mathrm{O}-\mathrm{Ni}$ [9]. Additionally, the characteristic peaks of $\mathrm{Ni}^{-\mathrm{OTiO}_{2}}$ and O-O stretching vibration were identified around 609.88 and $854.49 \mathrm{~cm}^{-1}$. The peaks around $1,380 \mathrm{~cm}^{-1}$ caused by substitution of the $\mathrm{Ni}^{2+}$ in place $\mathrm{Ti}^{4+}$ lattice sites $[27,28]$. On other hand, the physically adsorbed water from $\mathrm{H}-\mathrm{O}-\mathrm{H}$ bending vibration, which was identified from the sharp peak at $1,630 \mathrm{~cm}^{-1}$. In contrast to pure $\mathrm{TiO}_{2}$, the Ti-O peaks for Ni doped $\mathrm{TiO}_{2}$ occurred at higher wavenumbers. For instance, Ti-O stretching bond of pure $\mathrm{TiO}_{2}$ and $\mathrm{Ni}-\mathrm{OTiO}_{2}$ were identified at 544 and $609.88 \mathrm{~cm}^{-1}$, respectively. This could be due to the incorporation of $\mathrm{Ni}^{2+}$ into the $\mathrm{TiO}_{2}$ crystal structure which was further validated by XPS and confirmed by XRD. The high-resolution XPS spectra showed the chemical state of the elements and its effect in pure $\mathrm{TiO}_{2}$ and Ni-doped $\mathrm{TiO}_{2}$ (Fig. 3). The characteristics peak of $\mathrm{Ti} 2 \mathrm{p}_{3 / 2}$ and $\mathrm{Ti} 2 \mathrm{p}_{1 / 2}$ found at 458.89 and $464.77 \mathrm{eV}$, respectively indicated the existence of $\mathrm{Ti}^{4+}$ species [29]. On comparison of undoped $\mathrm{TiO}_{2}$, two distinct 

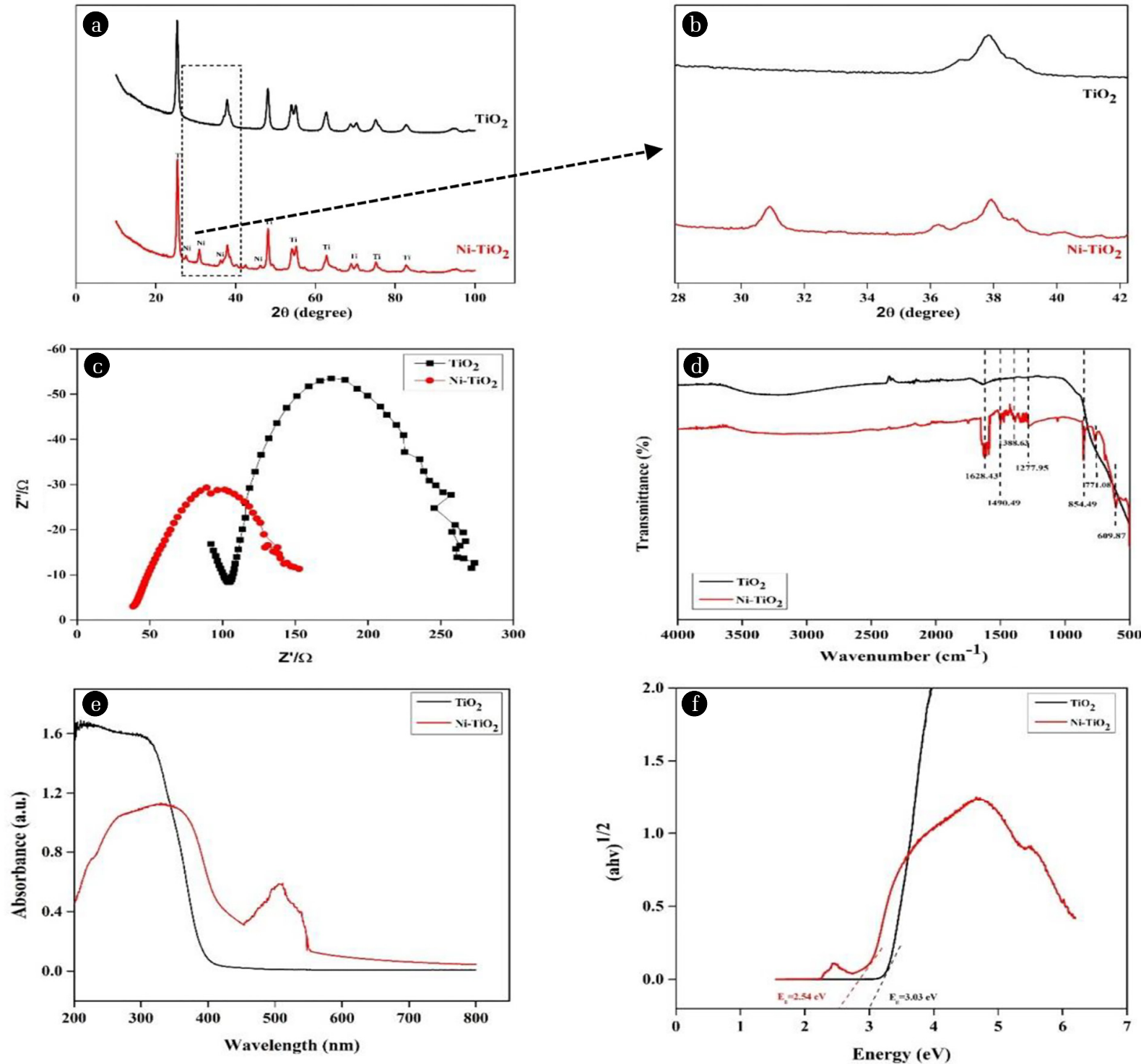

Fig 1. (a) XRD;(b) magnified XRD; (c) Nyquist plot; (d) FTIR; (e) DRS-spectra; and (f) Kubelka - Munk function photocatalysts TiO ${ }_{2}$ and $\mathrm{Ni}^{-T i \mathrm{O}_{2}}$.

peaks attributed to $\mathrm{Ni} 2 \mathrm{p}_{3 / 2}$ and $\mathrm{Ni} 2 \mathrm{p}_{1 / 2}$ at binding energies of 854.3 and $872.1 \mathrm{eV}$ were observed. The presence of a Ni-O band is suggested by the difference between these peaks, which is 17.6 $\mathrm{eV}$ [30]. This slightly shifting of the binding energy of Ti $2 p$ corresponding to $\mathrm{Ti} 2 \mathrm{p}_{3 / 2}$ and $\mathrm{Ti} 2 \mathrm{p}_{1 / 2}$, respectively in $\mathrm{Ni}-\mathrm{TiO}_{2}$ (Fig. 3(b)). The photoelectron peaks of the oxygen lattice (O 1s) in Ni-doped $\mathrm{TiO}_{2}$ i.e 529.76 is slightly lower than $530.15 \mathrm{eV}$ of undoped $\mathrm{TiO}_{2}$ (Fig. 3(d)). Thus, change in state of oxygen and intensity of peak slightly toward the higher binding energy due to the difference in electronegativity of both element $(\mathrm{Ti}=1.54$ and $\mathrm{Ni}=$ 1.91) [31]. Consequently, transformation of titanium ions to higher valent state takes place by releasing plethoric electron to achieve charge balance in the $\mathrm{TiO}_{2}$ lattice following the introduction of $\mathrm{Ni}^{2+}$ [32]. Thus, this indicated the incorporation of $\mathrm{Ni}^{2+}$ ions in $\mathrm{TiO}_{2}$ lattice of Ni-doped $\mathrm{TiO}_{2}$ sample [25]. The surface hydroxyl group or chemisorbed water molecules also reflects peak in Ni-doped $\mathrm{TiO}_{2}$ at $532.30 \mathrm{eV}$ [33]. These observation has been ascribed the successful formation of bond among $\mathrm{Ni}-\mathrm{O}-\mathrm{Ti}$ in the $\mathrm{Ni}^{-\mathrm{TiO}_{2}}$ material [10].

UV-vis spectrum analysis was used to determine the electronic structure of the samples, which provides the optical properties (such as absorption and band gap) through the irradiating light intensity. Kubelka-Munk and Tauc's plots were used to convert the reflectance spectra for bandgap estimation (Fig. 1(e) and (f)). Undoped $\mathrm{TiO}_{2}$ and $\mathrm{Ni}$ doped $\mathrm{TiO}_{2}$ showed absorption bands ranging from 200 to $300 \mathrm{~nm}$ and 400 to $500 \mathrm{~nm}$, respectively. It has also been observed that photocatalytic efficiency of Ni doped $\mathrm{TiO}_{2}$ is significant in the UVA lamp used in the experiment. Undoped $\mathrm{TiO}_{2}(3.03 \mathrm{eV})$ showed significant absorption below $400 \mathrm{~nm}$ due to the charge transfer between ligand $\left(\mathrm{O}^{2-}\right)$ and metal 

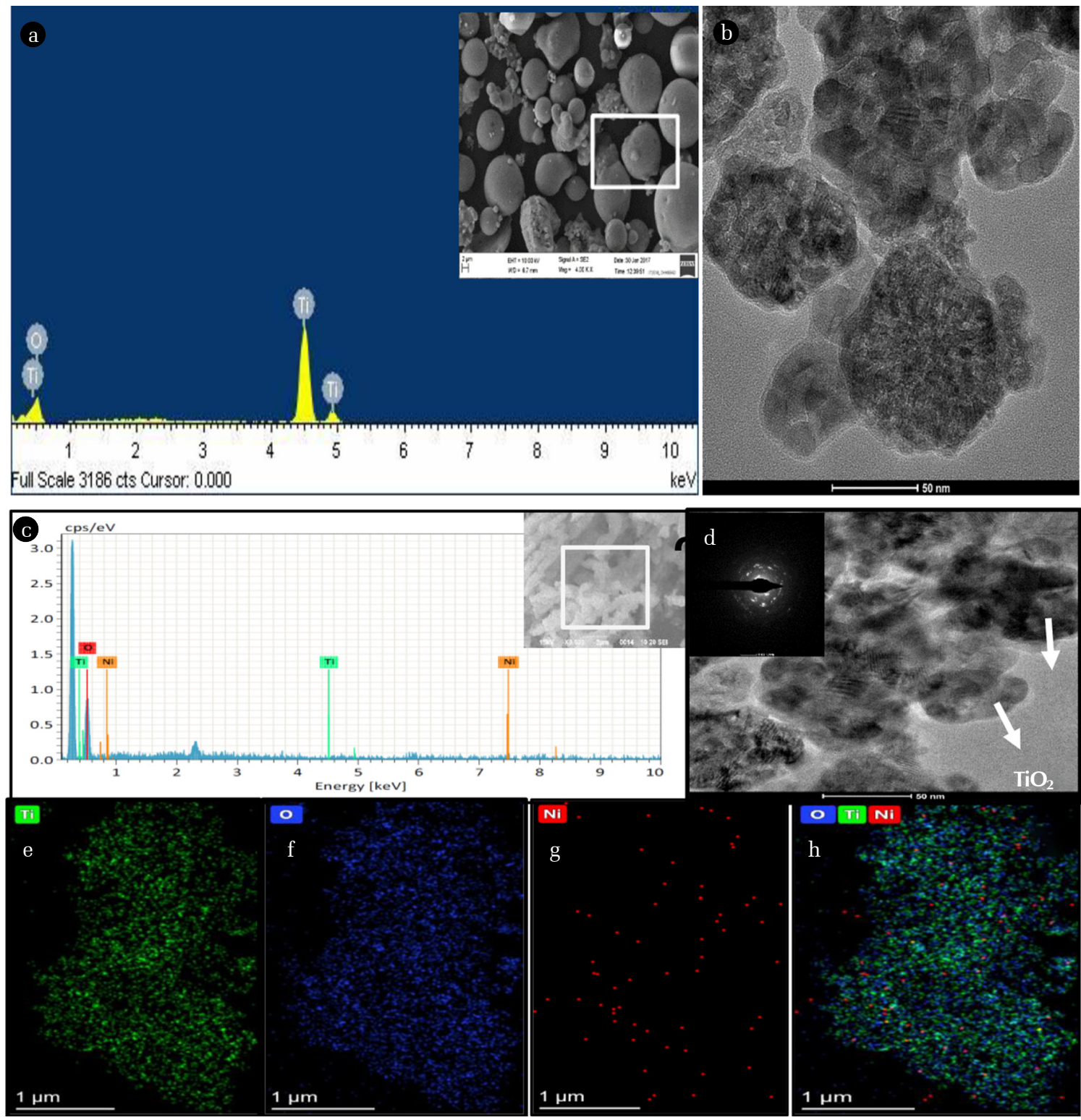

Fig. 2. (a), (b) SEM, TEM, SAED and EDS images of photocatalysts $\mathrm{TiO}_{2}$; and (c) $\sim$ (h) $\mathrm{Ni}^{-\mathrm{TiO}_{2}}$.

ion $\left(\mathrm{Ti}^{4+}\right)$ [34]. However, doping of nickel ion causes new electronic states in $\mathrm{TiO}_{2}$, which led to the narrowing of band gap and shifting of absorption into the visible region of $\mathrm{Ni}^{-} \mathrm{TiO}_{2}(2.54 \mathrm{eV})$. This electronic transition occurs from the valence band ( $2 p$ level of oxygen) to conduction band (3d level of titanium) in pure $\mathrm{TiO}_{2}$. As a result of doping $\mathrm{Ni}^{2+}$ ions into the $\mathrm{TiO}_{2}$ lattice, a Schottky barrier forms at the interface, which inhibiting electron-hole recombination. The electron transport from $\mathrm{Ni}^{2+}$ (3d) to $\mathrm{TiO}_{2}$ conduction band is aided by this interfacial barrier [35]. Thus, obtained results demonstrated that $\mathrm{Ni}^{2+}$ doping could alter the crystalline structure, lowers the band energies, and widen the optical properties to the visible light.

The electrochemical impedance spectroscopy (EIS) provides information about the electrical property of material. The charge transfer process and the solid electrolyte interface film are responsible for the two semicircles in the high-to-medium frequency range, respectively. The Nyquist plot is drawn between the real and imaginary parts of the impedance, and a smaller arc radius indicates that photogenerated electron-hole pairs are effectively separated, and that interfacial charge transfer is rapid. The result shows the smallest arc radius of EIS Nyquist plot in Ni-incorporated material, which is indicating the most effective separation of electron-hole pairs and the fastest interfacial charge transfer (Fig. 1(c)) [36].

The surface area of pure $\mathrm{TiO}_{2}$ was $5.71 \mathrm{~m}^{2} \mathrm{~g}^{-1}$ and increased to $12.19 \mathrm{~m}^{2} \mathrm{~g}^{-1}$ for $\mathrm{Ni}^{-\mathrm{TiO}_{2}}$ materials. The increase in surface area implying the presence of $\mathrm{Ni}^{2+}$ in $\mathrm{TiO}_{2}$ lattice with their small crystallite sizes of $\mathrm{Ni}^{-\mathrm{TiO}_{2}}$ materials [37]. 

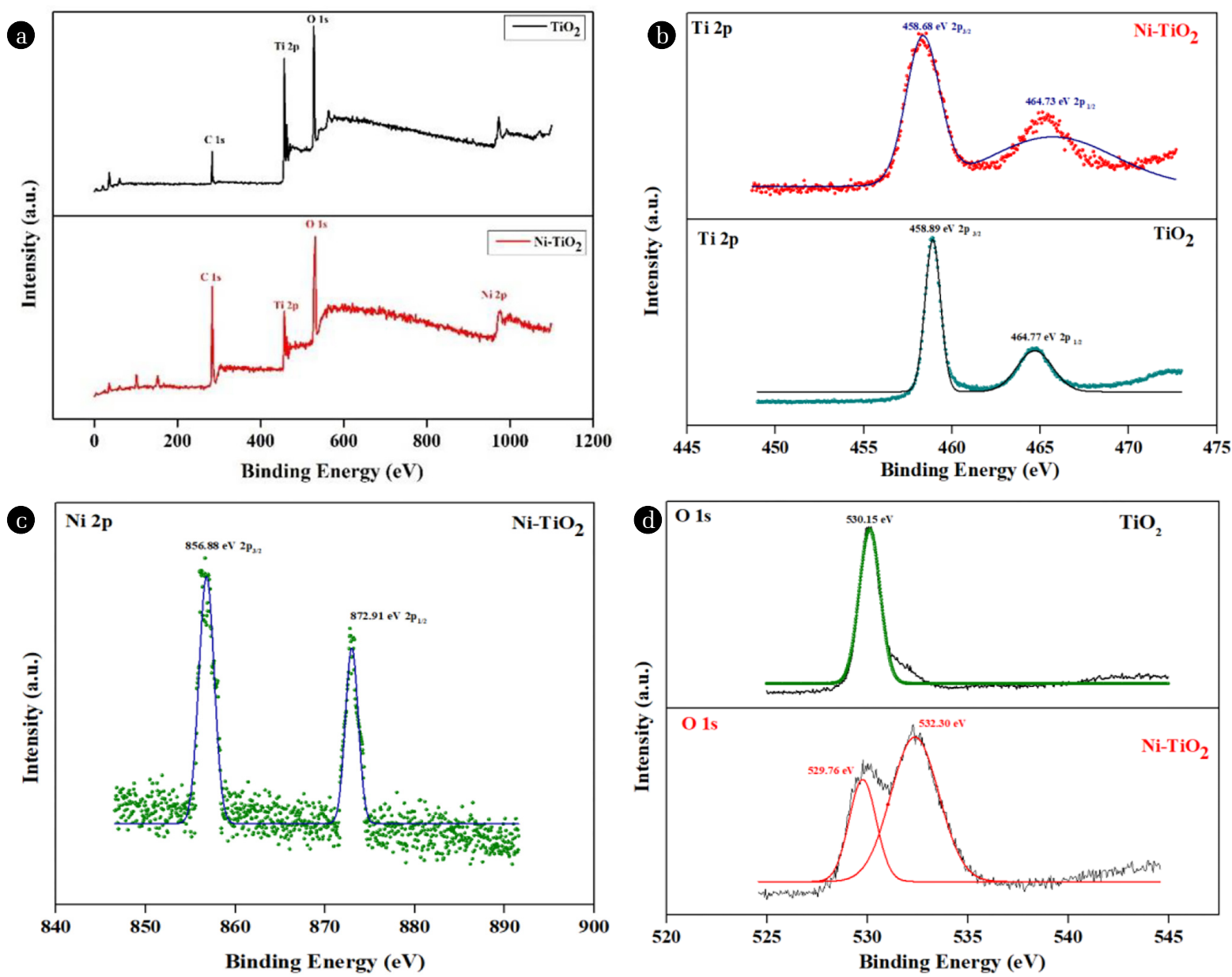

Fig. 3. XPS spectra of photocatalysts $\mathrm{TiO}_{2} ;$ and $\mathrm{Ni}-\mathrm{TiO}_{2}$.

\subsection{Regression Analysis for Photocatalytic Activity of Photocatalyst on CHD Removal}

ANOVA is one of the statistical tools which is used to determine the significance and accuracy of quadratic model developed through response surface methodology. The regression analysis was carried out in order to obtain a good fit in the response function and to predict the catalytic behaviour of the photocatalyst using quadratic equation in terms of $\mathrm{CHD}$ removal efficiency. The three-dimensional response surface plots of CHD reduction over different catalyst have been shown in Fig. S1. The quadratic model has been developed to predict the catalytic activity and $\mathrm{CHD}$ removal as a function of $\mathrm{X}_{1}(\mathrm{~S} / \mathrm{C}), \mathrm{X}_{2}(\mathrm{pH}), \mathrm{X}_{3}($ Time) and calculated as three first order effect $\left(\mathrm{X}_{1}, \mathrm{X}_{2}\right.$ and $\left.\mathrm{X}_{3}\right)$, interaction effect $\left(\mathrm{X}_{1} \mathrm{X}_{2}, \mathrm{X}_{1} \mathrm{X}_{3}\right.$ and $\left.\mathrm{X}_{2} \mathrm{X}_{3}\right)$ and three second order effect $\left(\mathrm{X}_{1}^{2}, \mathrm{X}_{2}^{2}\right.$ and $\left.\mathrm{X}_{3}^{2}\right)$. A polynomial model was used to represent the effects of individual parameters as well as their synergistic interactive effects on the response variable in Eqs. (6) and (7).

$$
\begin{gathered}
\text { CHD removal \% }\left(\mathrm{TiO}_{2}\right) \gamma=44.97-3.35 \mathrm{X}_{1}+ \\
8.69 \mathrm{X}_{2}+3.42 \mathrm{X}_{3}+0.92 \mathrm{X}_{1} \mathrm{X}_{2}-0.044 \mathrm{X}_{2} \mathrm{X}_{3}-12 \mathrm{X}_{1}^{2}- \\
0.84 \mathrm{X}_{2}^{2}-1.79 \mathrm{X}_{3}^{2}
\end{gathered}
$$

$$
\begin{gathered}
\text { CHD removal \% }\left(\mathrm{N}-\mathrm{TiO}_{2}\right) \quad \gamma=47.19-2.66 \mathrm{X}_{1}+ \\
9.32 \mathrm{X}_{2}+4.02 \mathrm{X}_{3}-2.26 \mathrm{X}_{1} \mathrm{X}_{2}-0.54 \mathrm{X}_{1} \mathrm{X}_{3}+ \\
1.17 \mathrm{X}_{2} \mathrm{X}_{3}-14.32 \mathrm{X}_{1}^{2}-2.41 \mathrm{X}_{2}^{2}-2.62 \mathrm{X}_{3}^{2}
\end{gathered}
$$

The results of the analysis of variance (ANOVA) (Table S3) represent the suitable model for photocatalyst during photocatalysis process. The P-value of the model, for both the photocatalyst, was $<0.0001$, and the F-value was 27.84 and 396.87 for $\mathrm{TiO}_{2}$ and $\mathrm{Ni}-\mathrm{TiO}_{2}$ respectively. These results confirmed that the model was highly significant, which is supported by the close agreement between the predicted and observed values. The $\mathrm{R}^{2}$ values were obtained 0.9616, and 0.9970 for $\mathrm{TiO}_{2}$ and $\mathrm{Ni}-\mathrm{TiO}_{2}$, respectively, which implies good correlation in actual and predicted values for $\mathrm{CHD}$ removal and further confirmed the reliability of model [38]. Smaller $\mathrm{P}>\mathrm{F}(<0.05)$ values show the significance of the particular model and the higher contribution towards the response variable, while the greater P-value of terms indicates the insignificance of the model.

\subsection{Photocatalytic Degradation and Mineralization Efficiency} The photocatalytic performance of prepared catalyst compared to 

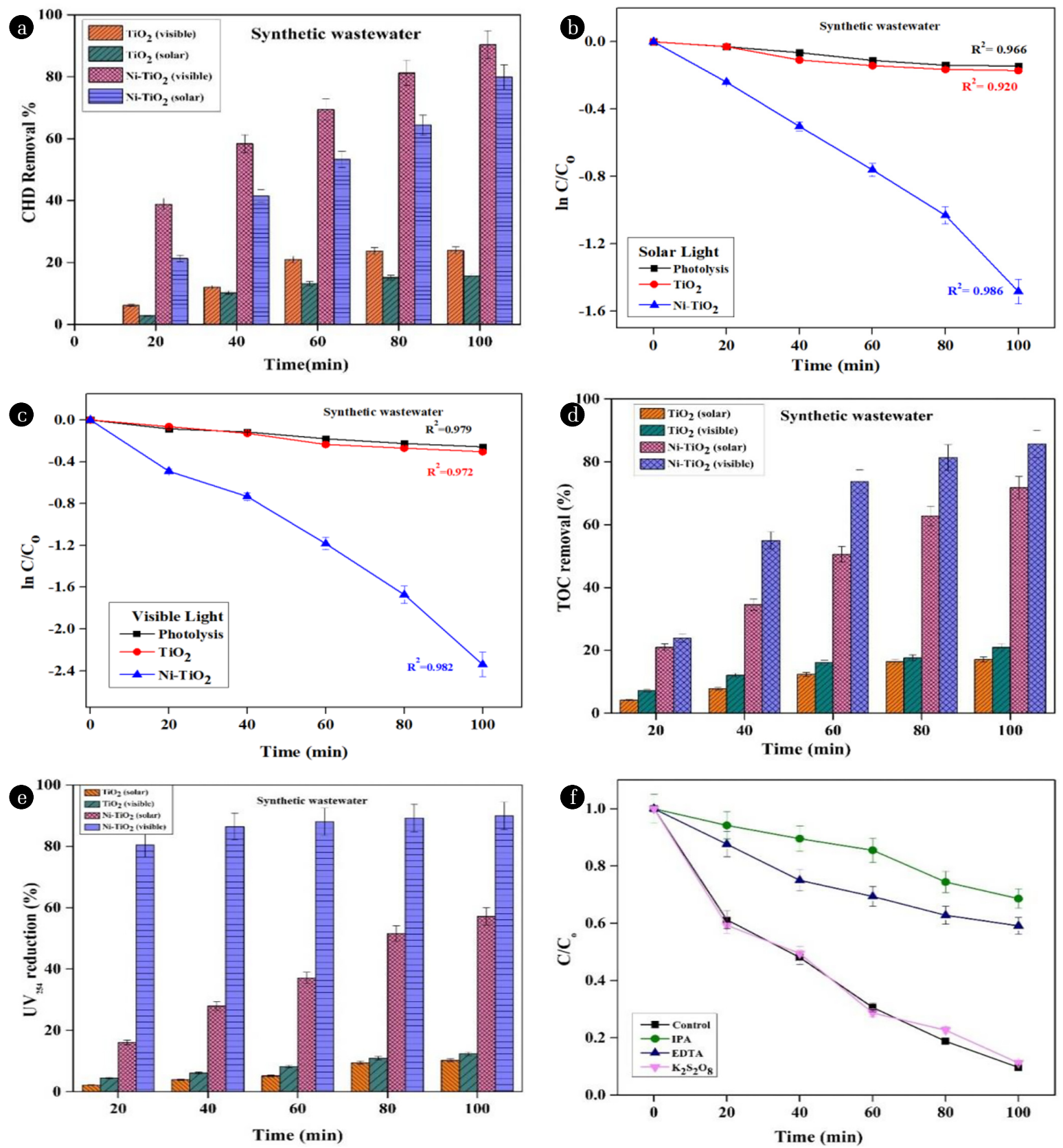

Fig 4. Photocatalytic removal of (a) CHD under solar and visible light; (b) pseudo-first order kinetic model under solar light; (c) pseudo-first order kinetic model under visible light; (d) TOC removal; (e) UV absorbance reduction and (f) Trapping experiment of photocatalysts $\mathrm{TiO}_{2} ;$ and $\mathrm{Ni}-\mathrm{TiO}_{2}$.

$\mathrm{TiO}_{2}$ was investigated under simulated visible light and natural sunlight (winter season) for removal of $\mathrm{CHD}$ from synthetic water and formulated wastewater under optimized conditions. The results showed higher removal efficiency of $\mathrm{Ni}^{-\mathrm{TiO}_{2}}$ (90.34\%-visible and 79.26\%-solar light) as compared to $\mathrm{TiO}_{2}$ (23.64\%-visible and 15.69\%-solar light) under both simulated visible and solar light (Fig. 4(a)).

These photocatalytic results demonstrated that doping of transition metal onto $\mathrm{TiO}_{2}$ could improve the optical properties of
$\mathrm{Ni}-\mathrm{TiO}_{2}$ to visible range and give rise to new energy level in the bandgap of $\mathrm{TiO}_{2}$, which facilitates the inhibition of electron-hole recombination. SEM, EDX and TEM results demonstrated the modification of $\mathrm{TiO}_{2}$ and revealed the shape of synthesised material as a slightly elongated particle, with presence of characteristic element. XPS and XRD results revealed the amount and state of $\mathrm{Ni}^{2+}$ in $\mathrm{TiO}_{2}$ lattice that could promote the photocatalytic performance of prepared material. These results suggested that photocatalytic performance enhanced by doping 

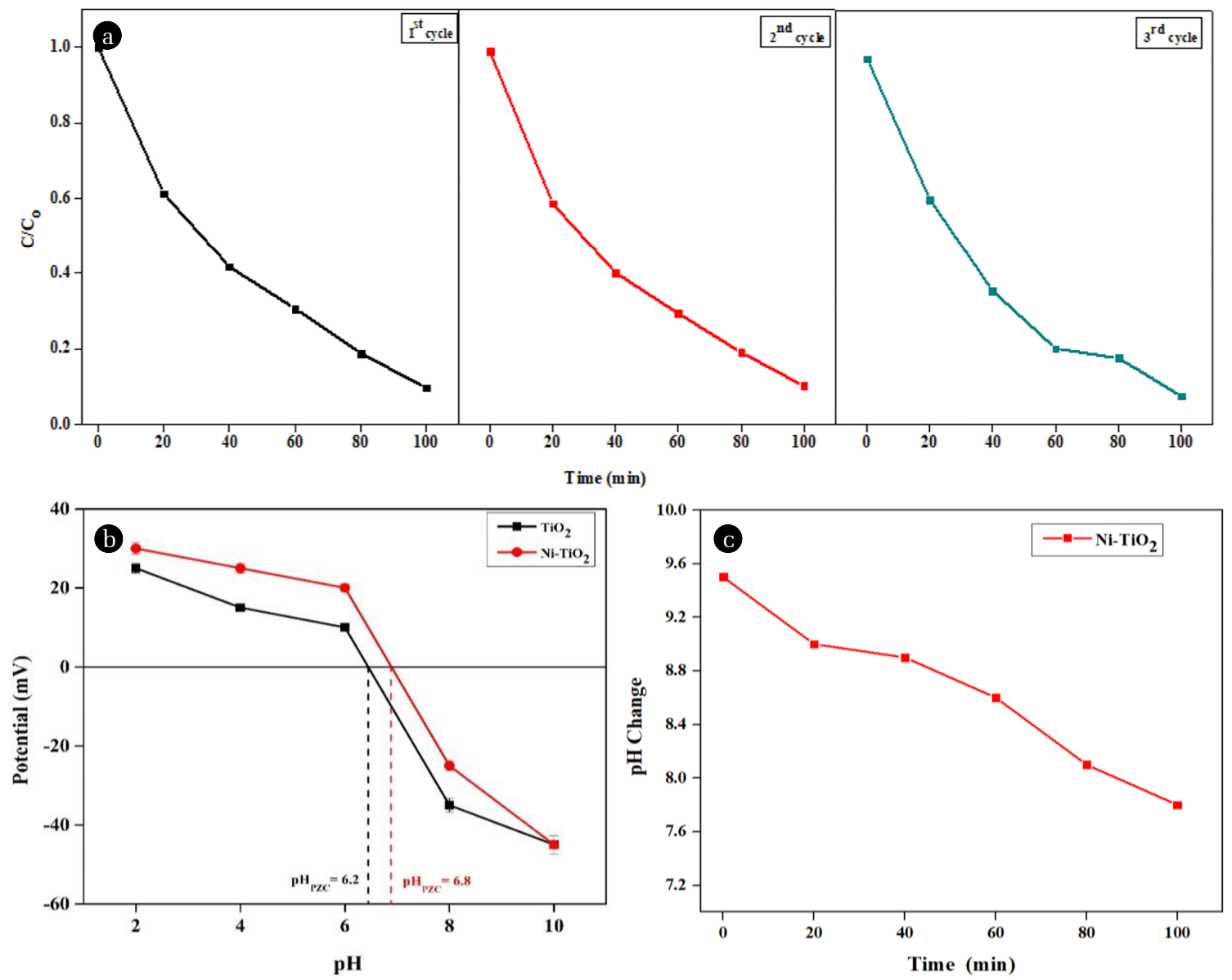

Fig 5. (a) Cycle experiment of $\mathrm{Ni}_{-} \mathrm{TiO}_{2}$ in photocatalytic degradation of $\mathrm{CHD}$ under optimized condition; (b) Zeta potential of $\mathrm{TiO}_{2}$ and $\mathrm{Ni}-\mathrm{TiO}{ }_{2}$ at different $\mathrm{pH}$ and (c) Effect of $\mathrm{pH}$ on $\mathrm{CHD}$ degradation $\mathrm{Ni}-\mathrm{TiO}_{2}$.

of cationic metal in $\mathrm{TiO}_{2}$ with small radii, which could occupy the lattice site of $\mathrm{Ti}^{4+}$ with more oxygen vacancies [39]. Therefore, extended light absorption properties of $\mathrm{Ni}^{-\mathrm{TiO}_{2}}$ to visible region leads to the investigation of photocatalytic activity of $\mathrm{Ni}^{-\mathrm{TiO}_{2}}$ under natural sunlight. The results depicted slight decrease in the removal efficiency of $\mathrm{Ni}-\mathrm{TiO}_{2}$ as compared to the visible region due to the variation in the intensity of sunlight [17]. This decreased solar intensity occurs due to the decrease in solar altitude and less transparency in the path of sunlight in the winter season [40]. Since, intensity of light is an important factor for the performance evaluation of a photocatalyst. Doping of metal on the surface of $\mathrm{TiO}_{2}$ can be accessible by hydroxyl group present on the surface of a material, which can trap both electron and hole generated. Evidently, trapping experiment has been carried out to evaluate the active radicals responsible for the mineralization process [41]. Isopropanol (IPA) (1\%), $1.0 \mathrm{mM}$ of potassium persulfate $\left(\mathrm{K}_{2} \mathrm{~S}_{2} \mathrm{O}_{8}\right)$ and ethylenediaminetetraacetic acid (EDTA) were used as scavengers of hydroxyl radicals $\left({ }^{\circ} \mathrm{OH}\right)$, electron $\left(\mathrm{e}^{-}\right)$, and holes $(\mathrm{h}+$ ), respectively (Fig. 4(f)). This result indicates that IPA and EDTA inhibited the CHD degradation and further confirms that ${ }^{\circ} \mathrm{OH}$ and $\mathrm{h}+$ were dominating reactive species. Therefore, the effect of photogenerated reactive species was found as de- creased in order of ${ }^{\circ} \mathrm{OH}>\mathrm{h}+>\mathrm{e}^{-}$. Therefore, it can be assumed that the generation of reactive species was influenced by intensity of sunlight which led to lowers the photocatalytic activity of $\mathrm{Ni}-\mathrm{TiO}_{2}$ sample.

Apart from light absorption, solution $\mathrm{pH}$, surface charge and surface area of the catalyst are also responsible for high photocatalytic activity of $\mathrm{Ni}-\mathrm{TiO}_{2}$ compared to $\mathrm{TiO}_{2}$. The point zero charge $\left(\mathrm{pH}_{\mathrm{PZC}}\right)$ was measured to evaluate the surface charge of $\mathrm{TiO}_{2}$ (6.2) and $\mathrm{Ni}^{-\mathrm{TiO}_{2}}$ (6.8), respectively (Fig. 5(b)). The surface of catalysts was positively charged at the $\mathrm{pH}$ lower than their $\mathrm{pH}_{\mathrm{PZC}}$ values and negatively charged at the $\mathrm{pH}$ higher than their $\mathrm{pH}_{\mathrm{PZC}}$ values. Thus, higher degradation and mineralization of $\mathrm{CHD}$ takes place in alkaline condition $(\mathrm{pH}=9.5)$, where surface of catalyst is negatively charged i.e. $\mathrm{pH}>\mathrm{pH}_{\mathrm{PZC}}$ and $\mathrm{CHD}$ ( $\mathrm{pKa}=2.2$ and 10.8) remain protonated which facilitates the interaction of catalyst and pollutant through electrostatic interaction [42]. Hence, alkaline condition enhances the photocatalysis process because the formation of hydroxyl radicals increased due to sufficient availability of $\mathrm{OH}^{-}$in the reaction mixture.

The photocatalytic performance of $\mathrm{Ni}-\mathrm{TiO}_{2}$ was investigated by using Langmuir-Hinshelwood (L-H) kinetic model, based on pseudo-first-order kinetics (Eq. (2), (3)) for a solid-liquid interface. 

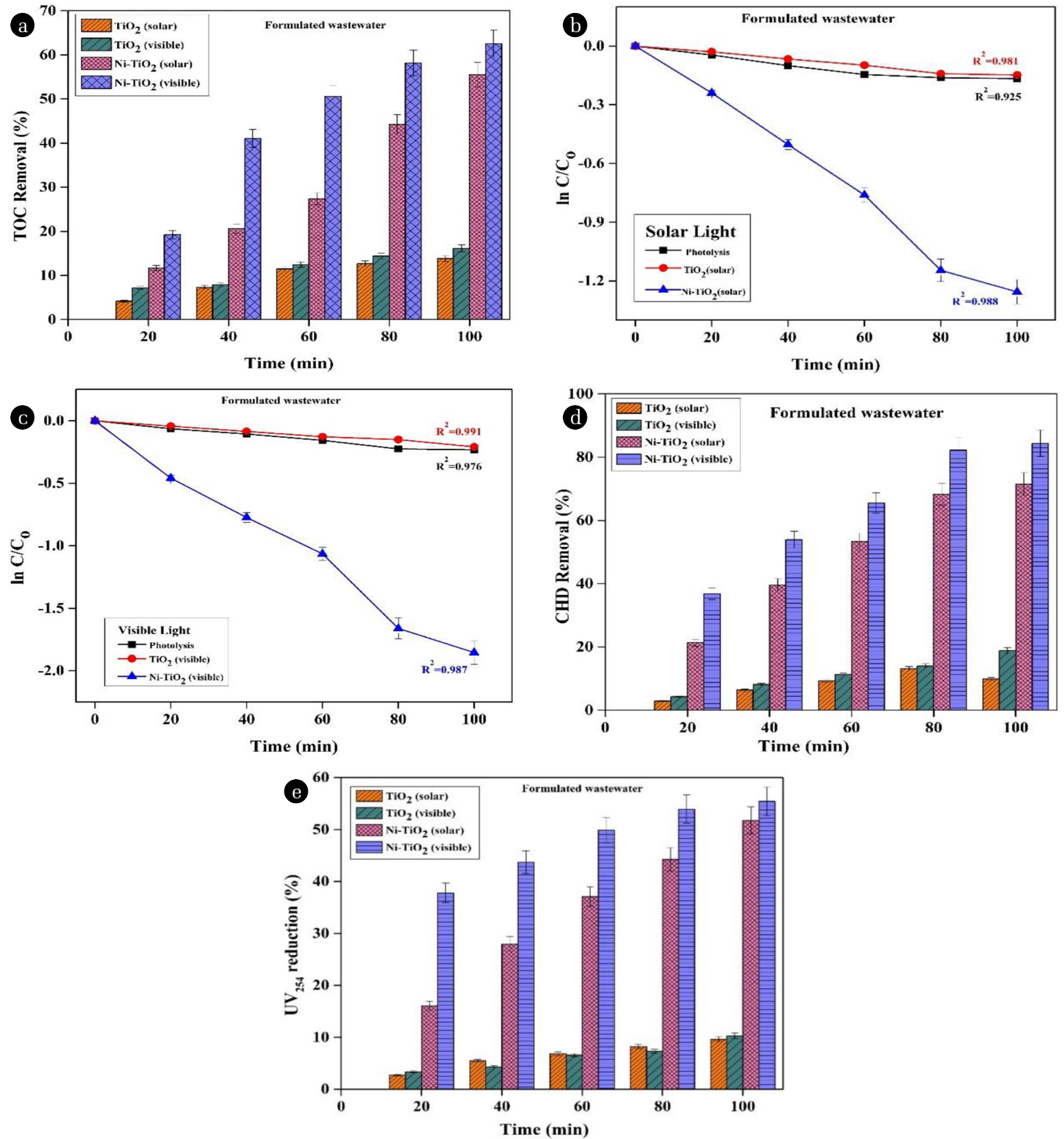

Fig. 6. Photocatalytic removal of formulated wastewater (a) CHD; (b) pseudo-first order kinetic model under solar light; (c) pseudo-first order kinetic model under visible light; (d) TOC removal; (e) UV absorbance reduction using $\mathrm{TiO}_{2}$; and $\mathrm{Ni}-\mathrm{TiO}_{2}$.

Rate of reaction found by plotting the graph among $\ln \left(\mathrm{C} / \mathrm{C}_{0}\right)$ versus $t$ (Fig. 4). The rate of reaction decreases under solar light due to the variation of light intensity during the experiment. The results showed that photocatalysis of synthetic wastewater using $\mathrm{Ni}-\mathrm{TiO}_{2}$ under simulated visible light and sunlight well fitted with pseudo-first kinetic order (Table 1). Among various photocatalytic conditions, $\mathrm{Ni}^{-\mathrm{TiO}_{2}}$ showed highest $\mathrm{k}_{\mathrm{CHD}}$ of 0.024 $\min ^{-1}$ under optimized condition. Considering the fact that increasing the surface area enhanced the photocatalytic reaction rate because photocatalysis mainly occur on the surface of cata- lyst [43]

For industrial application and better understanding of the photocatalytic efficiency of prepared catalyst, comparative studies have been carried out to treat formulated wastewater. The results demonstrated that removal efficiency of $\mathrm{Ni}^{-\mathrm{TiO}_{2}}$ deduced for formulated wastewater treatment due to interference of other ions (Fig. 6(a) (e)). The use of $\mathrm{Ni}^{-\mathrm{TiO}_{2}}$ for the removal of organic pollutant could be scaled-up under sunlight because of cost effective, reusability and easy applicability even though removal efficiency decreased. 
Table 1. PFO Model Kinetic Parameters of Chlorhexidine Digluconate (CHD) Degradation by Different Photocatalyst during UV, Visible and Solar Photocatalysis

\begin{tabular}{|c|c|c|c|c|c|}
\hline Photocatalysts & Experimental conditions & Removal efficiency & $\mathbf{R}^{2}$ & $k_{\text {obs }}$ value $\left(\mathrm{min}^{-1}\right)$ & Light source \\
\hline \multirow{4}{*}{$\mathrm{TiO}_{2}$} & $\begin{array}{l}\mathrm{C}_{o}=30 \mathrm{mgL}^{-1}, \mathrm{~S} / \mathrm{C}=1.8 \\
\mathrm{pH}=7.6, \text { Synthetic water }\end{array}$ & 23.64 & 0.974 & 0.003 & visible light \\
\hline & $\begin{array}{c}\mathrm{C}_{\mathrm{o}}=30 \mathrm{mgL}^{-1}, \mathrm{~S} / \mathrm{C}=1.63 \\
\mathrm{pH}=8.2, \text { Synthetic water }\end{array}$ & 15.69 & 0.92 & 0.001 & sunlight \\
\hline & $\begin{array}{c}\mathrm{C}_{0}=30 \mathrm{mgL}^{-1}, \mathrm{~S} / \mathrm{C}=1.8 \\
\mathrm{pH}=7.6, \text { formulated wastewater }\end{array}$ & 20.07 & 0.97 & 0.0028 & visible light \\
\hline & $\begin{array}{c}\mathrm{C}_{\mathrm{o}}=30 \mathrm{mgL}^{-1}, \mathrm{~S} / \mathrm{C}=1.63 \\
\mathrm{pH}=8.2, \text { formulated wastewater }\end{array}$ & 9.45 & 0.962 & 0.0035 & sunlight \\
\hline \multirow{4}{*}{$\mathrm{Ni}-\mathrm{TiO}_{2}$} & $\begin{array}{c}\mathrm{C}_{\mathrm{o}}=30 \mathrm{mgL}^{-1}, \mathrm{~S} / \mathrm{C}=1.54 \\
\mathrm{pH}=9.2, \text { Synthetic water }\end{array}$ & 90.34 & 0.982 & 0.0245 & visible light \\
\hline & $\begin{array}{l}\mathrm{C}_{\mathrm{o}}=30 \mathrm{mgL}^{-1}, \mathrm{~S} / \mathrm{C}=1.98 \\
\mathrm{pH}=7.89, \text { Synthetic water }\end{array}$ & 79.26 & 0.986 & 0.0119 & sunlight \\
\hline & $\begin{array}{c}\mathrm{C}_{o}=30 \mathrm{mgL}^{-1}, \mathrm{~S} / \mathrm{C}=1.54 \\
\mathrm{pH}=9.2, \text { formulated wastewater }\end{array}$ & 90.34 & 0.976 & 0.022 & visible light \\
\hline & $\begin{array}{c}\mathrm{C}_{\mathrm{o}}=30 \mathrm{mgL}^{-1}, \mathrm{~S} / \mathrm{C}=1.98, \\
\mathrm{pH}=7.89, \text { formulated wastewater }\end{array}$ & 79.26 & 0.986 & 0.239 & sunlight \\
\hline
\end{tabular}

\subsection{Possible Pathway and Toxicity Test}

The performance of photocatalyst was also estimated in terms of TOC removal and reduction of $\mathrm{UV}_{254}$. The oxidation process produces more harmful intermediates than the parent compound, which can be assessed using UV absorbance. The reactive organic fraction of wastewater loaded with organic pollutant is measured at a wavelength of $\mathrm{UV}_{254} \mathrm{~nm}$.

The overall reaction during photo mineralization of $\mathrm{CHD}$ in the excess of oxygen under optimized experimental condition is validated by the equation (Eq. (8)) given below:

$$
\begin{gathered}
\mathrm{C}_{34} \mathrm{H}_{54} \mathrm{Cl}_{2} \mathrm{~N}_{10} \mathrm{O}_{7}+36 \mathrm{O}_{2}+\mathrm{h} 9(370-400 \mathrm{~nm}) \rightarrow \\
34 \mathrm{CO}_{2}+10 \mathrm{NH}_{3}+2 \mathrm{HCl}+11 \mathrm{H}_{2} \mathrm{O}
\end{gathered}
$$

As can be observed, reduction in reactive organic fraction increased rapidly after $20 \mathrm{~min}$ during the photocatalytic process using $\mathrm{Ni}-\mathrm{TiO}_{2}$ under visible (89.92\%) and solar light (57.15\%) (Fig. 4(e)). This difference in removal efficiency may be explained by the availability of sufficient solar light to generate a significant number of reactive species for the degradation of parent compound and their intermediate. Moreover, leftover reactive organic species in reaction mixture after photocatalysis process may be due to the formation of intermediate, which need more time to be removed [44]. A similar trend of mineralization was observed, where $\mathrm{Ni}^{-} \mathrm{TiO}_{2}$ (85.71\%-visible and 71.79\%-solar light) showed highest TOC removal as compared to $\mathrm{TiO}_{2}$ (21.70\%-visible and $17.06 \%$-solar) under visible and solar light, respectively (Fig. 4(d)). The results were validated using chromatogram of HPLC (Fig. S6).The toxicity test has been carried out for the successful applicability of photocatalyst in solar as well as visible light.

The possible degraded by-product and pathway during $\mathrm{Ni}^{-\mathrm{TiO}_{2}}$ mediated photocatalysis of formulated wastewater under simulated visible light and solar light was investigated by LC-MS spectroscopy. The peak at 505 and $507 \mathrm{~m} / \mathrm{z}$ shows two isotopes of $\mathrm{Cl}$ atoms (35 and 37) attached to CHD in aqueous solution. This characteristics peak disappeared upon increasing the time during photocatalysis of formulated wastewater using $\mathrm{Ni}-\mathrm{TiO}_{2}$ under visible light process. According to LC/MS results, transformation of the characteristics peak to $453,316,221,127$ and $200 \mathrm{~m} / \mathrm{z}$ belongs to the intimidated products of photooxidation process. According to LC/MS results and literature available, a possible pathway was proposed by substitution and addition [45, 46] (Fig. S2(a) and S3). $\mathrm{OH}^{\circ}$ and $\mathrm{h}^{+}$ were produced as a reactive species in $\mathrm{Ni}^{-\mathrm{TiO}_{2}}$ mediated photocatalysis process, where $\mathrm{OH}^{\circ}$ was dominating in the photocatalytic oxidation was investigated by trapping experiment. $\mathrm{OH}^{\circ}$ attacked on benzene ring of $\mathrm{CHD}$ and involve breaking of $\mathrm{C}-\mathrm{Cl}$ bond i.e., dichlorination of aromatic ring takes place by addition of $\mathrm{OH}^{\mathrm{o}}$. Finally, resulted to the breakdown of biguanide moiety leads to the formation of smaller molecules of transformed products. In addition, quantification and mass identification of transformed product are beyond the scope of study.

Toxicological studies have been carried out to investigate the toxicity of transformed products. Bacillus cereus was subjected to bacterial susceptibility test, which is commonly found in human oral cavities. Inhibition zone of a standard solution of $\mathrm{CHD}, 30$ $\mathrm{mg} / \mathrm{L}$ concentration of sample, ciprofloxacin and amoxicillin antibiotics was 30, 15, 50 and $3 \mathrm{~mm}$ in diameter (Fig. S4). Negligible inhibition zone was observed for the degraded product after photocatalytic degradation of CHD. From the obtained results, it can be foreseen that the transformed products after photocatalytic degradation of $\mathrm{CHD}$ using $\mathrm{Ni}^{-\mathrm{TiO}_{2}}$ as a photocatalyst are non-toxic upon release in the environment.

Thus, higher mineralization of $\mathrm{CHD}$ was found using $\mathrm{Ni}-\mathrm{TiO}_{2}$ as a photocatalyst under simulated visible light because modification of $\mathrm{TiO}_{2}$ enhanced the absorption of light with the wavelength $>400 \mathrm{~nm}$ and promotes the formation of sufficient number of reactive species. This reactive species attack phenyl ring of CHD during oxidation process and break up into short-carbon compounds. Atomic adsorption analysis of treated wastewater has been carried out to check the metal leaching during photocatalysis 
Table 2. Energy Consumption in Synthetic and Formulated Wastewater Treatment Using Photocatalyst under Different Treatment Condition

\begin{tabular}{|c|c|c|c|c|c|c|}
\hline Photocatalysts & Experimental conditions & $\begin{array}{l}\text { Removal } \\
\text { efficiency }\end{array}$ & $\begin{array}{c}\text { Working } \\
\text { volume (L) }\end{array}$ & $\begin{array}{l}\text { Reaction } \\
\text { time (h) }\end{array}$ & $\begin{array}{c}\text { Power } \\
\text { Consumption }(\mathrm{W})\end{array}$ & $\begin{array}{c}\text { Power consumed/ } \\
\text { CHD removal }\left(\mathrm{kWhkg}^{-1}\right)\end{array}$ \\
\hline \multirow{4}{*}{$\mathrm{TiO}_{2}$} & $\begin{array}{c}\mathrm{C}_{0}=30 \mathrm{mgL}^{-1}, \mathrm{~S} / \mathrm{C}=1.8, \\
\mathrm{pH}=7.6, \text { Synthetic water and visible light }\end{array}$ & 23.64 & 0.2 & 0.003 & 0.2 & 7.55 \\
\hline & $\begin{array}{c}\mathrm{C}_{0}=30 \mathrm{mgL}^{-1}, \mathrm{~S} / \mathrm{C}=1.63, \mathrm{pH}=8.2 \text {, Synthetic } \\
\text { water and sunlight }\end{array}$ & 15.69 & 0.2 & 0.001 & 1.17 & 70.66 \\
\hline & $\begin{array}{c}\mathrm{C}_{0}=30 \mathrm{mgL}^{-1}, \mathrm{~S} / \mathrm{C}=1.8, \\
\mathrm{pH}=7.6 \text {, formulated wastewater and Visible light }\end{array}$ & 18.79 & 0.2 & 0.0028 & 0.2 & 11.96 \\
\hline & $\begin{array}{c}\mathrm{C}_{0}=30 \mathrm{mgL}^{-1}, \mathrm{~S} / \mathrm{C}=1.63, \mathrm{pH}=8.2, \text { formulated } \\
\text { wastewater and sunlight }\end{array}$ & 9.49 & 0.2 & 0.0035 & 1.17 & 44.58 \\
\hline \multirow{4}{*}{$\mathrm{Ni}-\mathrm{TiO}_{2}$} & $\begin{array}{c}\mathrm{C}_{0}=30 \mathrm{mgL}^{-1}, \mathrm{~S} / \mathrm{C}=1.54, \\
\mathrm{pH}=9.2, \text { Synthetic water and visible light }\end{array}$ & 90.34 & 0.2 & 0.0245 & 0.2 & 1.88 \\
\hline & $\begin{aligned} & \mathrm{C}_{o}=30 \mathrm{mgL}^{-1}, \mathrm{~S} / \mathrm{C}=1.98 \\
\mathrm{pH}= & 7.89, \text { Synthetic water and Sunlight }\end{aligned}$ & 79.26 & 0.2 & 0.0119 & 1.17 & 14.59 \\
\hline & $\begin{array}{c}\mathrm{C}_{0}=30 \mathrm{mgL}^{-1}, \mathrm{~S} / \mathrm{C}=1.54, \\
\mathrm{pH}=9.2 \text {, formulated wastewater and visible light }\end{array}$ & 84.34 & 0.2 & 0.022 & 0.2 & 1.94 \\
\hline & $\begin{array}{c}\mathrm{C}_{0}=30 \mathrm{mgL}^{-1}, \mathrm{~S} / \mathrm{C}=1.98, \\
\mathrm{pH}=7.89, \text { formulated wastewater and sunlight }\end{array}$ & 71.51 & 0.2 & 0.239 & 1.17 & 14.68 \\
\hline
\end{tabular}

process. The analysis result indicated that the leaching concentration of $\mathrm{Ni}$ in treated water was found to be below detection limit depicting the stability of prepared catalyst during photocatalysis process [47].

\subsection{Correlation between Spectroscopic indices and miner- alization of $\mathrm{CHD}$ using $\mathrm{TiO}_{2}$ and $\mathrm{Ni}-\mathrm{TiO}_{2}$}

$\mathrm{CHD}$ is composed of phenyl aromatic carbon, presence of reactive and aromatic components in water after treatment referred as left-over organic compound. ASI could be the best way to quantify the left-over reactive organic compound in treated water in Eq. (4). Formation of aliphatic compounds and reduction in ASI, $\mathrm{UV}_{280}$ and TOC values in treated wastewater confirms the mineralization of CHD during photocatalysis reaction. ASI and TOC are considered as reactivity of activated aromatic group and oxidized organic carbon in terms of $\mathrm{CO}_{2}$ release. This spectral approach has been introduced to understand the cleavage of aromatic $\mathrm{C}=\mathrm{C}$ and decrease in hydrophobic compound in treated water during photocatalysis process, which is measured at $280 \mathrm{~nm}$ in UV-spectroscopy. This reduction in the value of aromatic $\mathrm{C}=\mathrm{C}$ content present in $\mathrm{CHD}$ with respect to time validated the reduction of TOC and mineralization of $\mathrm{CHD}$.

Reduction of ASI and $\mathrm{UV}_{280}$ was observed, which validates mineralisation process of organic compound through spectral approach. Due to the solubility of phenol, removal of phenyl containing compound might have one reason for drastic reduction in TOC through photocatalysis. However, dominating reactive species such as $\mathrm{OH}^{\bullet}$ and holes produced using $\mathrm{TiO}_{2}$ and $\mathrm{Ni}-\mathrm{TiO}_{2}$ mediated photocatalytic degradation of $\mathrm{CHD}$ (Fig. S5), the mineralization of CHD (90.34\%) with respect to TOC reduction (85.71\%), aromaticity reduction (ASI-59.66\%) and hydrophobic compound reduction $\left(\mathrm{UV}_{280^{-}}\right.$ $68.23 \%)$ was observed.

The comparative studies for photodegradation efficiencies of both the synthesised photocatalysts $\left(\mathrm{TiO}_{2}\right.$ and $\left.\mathrm{Ni}-\mathrm{TiO}_{2}\right)$, it was found that doped- $\mathrm{TiO}_{2}$ photocatalyst was efficient for removal of recalci- trant organic pollutant with respect to mineralization of targeted compound and also remove reactive hydrophobic as well as aromatic compound from organic pollutant loaded wastewater.

The mineralisation process of CHD through spectral approach with respect to TOC reduction, aromaticity reduction (ASI) and hydrophobic compound reduction $\left(\mathrm{UV}_{280}\right)$ was validated with HPLC results. The results showed decrease in characteristic peak of $\mathrm{CHD}$ with time after photocatalytic degradation process. Additionally, chromatogram of LC-MS confirms the breakdown of complex structure of CHD into smaller molecules due to presence of new peaks in the treated water. The interference and toxicity of transformed products were investigated with respect of reduction in ASI, TOC and $\mathrm{UV}_{280}$.

\subsection{Comparison of Degradation Efficiency of Photocatalyst under Simulated and Sunlight with Energy Consumption in Treatment Process}

The photocatalytic treatment of $\mathrm{CHD}$ using $\mathrm{TiO}_{2}$ and $\mathrm{Ni}-\mathrm{TiO}_{2}$ under simulated and solar light were depicted the higher mineralization in visible light. In order to cost-effectiveness and large-scale applicability of treatment process, energy consumption was investigated using Eq. (9) and (10), respectively [17].

$$
\begin{aligned}
& \text { Total power consumed }(k W h)= \\
& \frac{\text { Power used }(k W) \times \text { Reaction time }(h)}{60 \times 1000}
\end{aligned}
$$

Total power consumption per CHD removal $\left(\mathrm{kWhKg}^{-1}\right)=$

$$
\frac{\text { Power Concumption }(k W h)}{\left[\left(C_{O}-C_{f}\right) \times(\text { working volume }(L)]\right.}
$$

Where, $C_{o}$ and $C_{f}$ are the initial and final concentration of $\mathrm{CHD}$ in $\mathrm{KgL}^{-1}$. The energy consumption during photocatalytic treatment 
process for synthetic and formulated wastewater under simulated visible and sunlight was calculated. The experimental results showed higher mineralization for visible light as compared to the solar, which may be due to variation in intensity of solar light during the experiment led to the insufficient production of reactive species. Furthermore, energy was used simply for stirring during solar treatment, whereas visible mediated photocatalytic treatment required a high-powered lamp and stirrer. On comparing the treatment condition, sunlight mediated photocatalysis of synthetic wastewater using $\mathrm{Ni}^{-} \mathrm{TiO}_{2}$ showed lower energy consumption (1.87 $\mathrm{kWhkg}^{-1}$ ) with comparable CHD removal (79.26\%) than other treatment condition (Table 2). The reusability of prepared catalyst was also investigated, and results showed good stability even after 3 cycles. Additionally, $\mathrm{pH}$ of the treated water was found near 7 to 7.8 , which can be reused for a different purpose other than drinking (Fig. 5(a)).

Thus, results demonstrated that photocatalytic treatment of organic pollutant using $\mathrm{Ni}-\mathrm{TiO}_{2}$ under sunlight could be used as economical and energy-efficient treatment process for large scale treatment system.

\section{Conclusions}

The synthesized $\mathrm{Ni}-\mathrm{TiO}_{2}$ photocatalyst showed improved photocatalytic treatment due to the incorporation of $\mathrm{Ni}$ into the $\mathrm{TiO}_{2}$ lattice, exhibiting superior properties such as phase structure, crystallinity, crystallite size, morphology, separation of charge carriers and favourable for the shift of the bandgap into the visible region. SEM and TEM images confirmed the aggregation of particles and enhanced optical property due to the formation of bond between $\mathrm{Ni}$ and $\mathrm{O}$ atoms. The experimental results indicated removal of $\mathrm{CHD}$ using $\mathrm{Ni}-\mathrm{TiO}_{2}$ under simulated visible light and natural solar light was $\sim 90.34$ and $79.26 \%$, respectively. In addition, toxicity assessment of photooxidation products show the efficiency of treatment system and indicating the safe disposal of treated water into the aquatic environment. Thus, the preferential removal efficiency with lower energy consumption (1.87 $\mathrm{kWhKg}^{-1}$ ) indicated that $\mathrm{Ni}-\mathrm{TiO}_{2}$ mediated heterogeneous photocatalysis under sunlight could be used for a larg- scale treatment system.

\section{Acknowledgment}

The authors are very thankful for the financial support from Indian Institute of Technology (Indian School of Mines), Dhanbad under a Junior Research Fellowship scheme funded by Ministry of Human Resource Development (MHRD), Government of India, New Delhi to carry out this research work. We would also like to acknowledge Nanotechnology Research Centre (NRC), SRMIST for providing the instrumentation facilities.

\section{Conflict-of-Interest}

The authors declare that they have no conflict of interest.

\section{Author Contributions}

A.S. (Ph.D. student) did Conceptualization, Methodology, Investigation, Formal analysis \& Writing-Original Draft. B.K.M. (Associate Professor) did Supervision, Conceptualization, Writing - Review \& Editing.

\section{References}

1. Santiago-Morales J, Gómez MJ, Herrera-López S, FernándezAlba AR, García-Calvo E, Rosal R. Energy Efficiency for the Removal of Non-Polar Pollutants during Ultraviolet Irradiation, Visible Light Photocatalysis and Ozonation of a Wastewater Effluent. Water Res. 2013;47(15):5546-5556. https://doi.org/10. 1016/j.watres.2013.06.030.

2. Das R, Sarkar S, Bhattacharjee C. Photocatalytic Degradation of Chlorhexidine-A Chemical Assessment and Prediction of Optimal Condition by Response Surface Methodology. J. Water Process Eng.2014;2:79-86. https://doi.org/10.1016/j.jwpe.2014. 05.005 .

3. Khetan SK, Collins TJ. Human Pharmaceuticals in the Aquatic Environment: A Challenge to Green Chemistry Chem. Rev. 2007;107:2319-2364. https://doi.org/10.1021/cr020441w.

4. Majumder A, Gupta AK, Ghosal PS, Varma M. A Review on Hospital Wastewater Treatment: A Special Emphasis on Occurrence and Removal of Pharmaceutically Active Compounds, Resistant Microorganisms, and SARS-CoV-2. J. Environ. Chem. Eng. 2020;9(2):104812. https://doi.org/10.1016/j.jece.2020.104812.

5. Das R, Sarkar S, Chakraborty S, Choi H, Bhattacharjee C. Remediation of Antiseptic Components in Wastewater by Photocatalysis Using TiO2 Nanoparticles. Ind. Eng. Chem. Res. 2014;53(8):3012-3020. https://doi.org/10.1021/ie403817z.

6. Aziz KHH, Omer KM, Mahyar A, Miessner H, Mueller S, Moeller D. Application of Photocatalytic Falling Film Reactor to Elucidate the Degradation Pathways of Pharmaceutical Diclofenac and Ibuprofen in Aqueous Solutions. Coatings 2019;9(8):465. https://doi.org/10.3390/coatings9080465.

7. Liu ML, Chen B, Bin Li RS, Li CM, Zou HY, Huang CZ. Dendritic CuSe with Hierarchical Side-Branches: Synthesis, Efficient Adsorption, and Enhanced Photocatalytic Activities under Daylight. ACS Sustain. Chem. Eng. 2017;5(5):4154-4160. https:// doi.org/10.1021/acssuschemeng.7b00126.

8. Aziz KHH, Miessner H, Mahyar A, et al. Degradation of Perfluorosurfactant in Aqueous Solution Using Non-Thermal Plasma Generated by Nano-Second Pulse Corona Discharge Reactor. Arab. J. Chem. 2021;14(10):103366. https://doi.org/10.1016/j.arabjc.2021.103366.

9. Pavithra C, Madhuri W. Electrical and Magnetic Properties of NiTiO3 Nanoparticles Synthesized by the Sol-Gel Synthesis Method and Microwave Sintering. J. Mater. Res. Technol. 2019;8(3):3097-3101. https://doi.org/10.1016/j.jmrt.2017.07.007.

10. Blanco-Vega MP, Guzmán-Mar JL, Villanueva-Rodríguez M, et al. Photocatalytic Elimination of Bisphenol A under Visible Light Using Ni-Doped TiO2 Synthesized by Microwave Assisted Sol-Gel Method. Mater. Sci. Semicond. Process. 2017;71:275282. https://doi.org/10.1016/j.mssp.2017.08.013. 
11. Gabal MAEF Al, Angari YM, Obaid AY. Structural Characterization and Activation Energy of $\mathrm{NiTiO}_{3}$ Nanopowders Prepared by the Co-Precipitation and Impregnation with Calcinations. Comptes Rendus Chim. 2013;16(8):704-711. https://doi.org/10.1016/j.crci.2013.01.009.

12. Kumari S, Jose S, Tyagi M, Jagadevan S. A Holistic and Sustainable Approach for Recovery of Phosphorus via Struvite Crystallization from Synthetic Distillery Wastewater. J. Clean. Prod. 2020;254:120037. https://doi.org/10.1016/j.jclepro.2020. 120037.

13. Priya T, Mohanta VL, Mishra BK. Performance Evaluation of Zirconium Oxychloride for Reduction of Hydrophobic Fractions of Natural Organic Matter. Sep. Purif. Technol. 2017;174:104108. https://doi.org/10.1016/j.seppur.2016.10.003

14. Tu X, Meng X, Pan Y, Crittenden JC, Wang Y. Degradation Kinetics of Target Compounds and Correlations with Spectral Indices during UV/H2O2 Post-Treatment of Biologically Treated Acrylonitrile Wastewater. Chemosphere 2020;243:125384. https://doi.org/10.1016/j.chemosphere.2019.125384.

15. Guan B, Yu J, Guo S, Yu S, Han S. Porous Nickel Doped Titanium Dioxide Nanoparticles with Improved Visible Light Photocatalytic Activity. Nanoscale Adv. 2020;2(3):1352-1357. https://doi.org/10.1039/c9na00760a.

16. Kumari V, Tripathi AK. Characterization of Pharmaceuticals Industrial Effluent Using GC-MS and FT-IR Analyses and Defining Its Toxicity. Appl. Water Sci. 2019;9(8):1-8. https://doi. org/10.1007/s13201-019-1064-z.

17. Priyanka K, Remya N, Behera M. Comparison of Titanium Dioxide Based Catalysts Preparation Methods in the Mineralization and Nutrients Removal from Greywater by Solar Photocatalysis. J. Clean. Prod. 2019;235:1-10. https://doi.org/10.1016/j.jclepro.2019.06.314.18.

18. Nasseh N, Taghavi L, Barikbin B, Nasseri MA. Synthesis and characterizations of a novel $\mathrm{FeNi} / \mathrm{SiO} / \mathrm{CuS}$ magnetic nanocomposite for photocatalytic degradation of tetracycline in simulated wastewater. J. Clean. Prod. 2018;179:42-54. https://doi. org/10.1016/j.jclepro.2018.01.052

19. Priya T, Prakash P, Mishra BK. Understanding the Coagulant Activity of Zirconium Oxychloride to Control THMs Formation Using Response Surface Methodology. Ecotoxicol. Environ. Saf. 2018;159:28-37. https://doi.org/10.1016/j.ecoenv.2018.04.036.

20. Karlsson. Metallic Oxides with the Structure of High-Speed Steel Carbide. Nature 1951;1.

21. Rodríguez-González V, Ruiz-Gómez MA, Torres-Martínez LM, Gómez R. Photocatalytic Decomposition of Synthetic Alizarin Red S by Nickel Doped TiO2. Top. Catal. 2011;54(8-9):490-495. https://doi.org/10.1007/s11244-011-9612-2.22.

22. Sharma SD, Singh D, Saini KK, et al. Sol-Gel-Derived Super-Hydrophilic Nickel Doped TiO2 Film as Active Photo-Catalyst. Appl. Catal. A Gen. 2006;314(1):40-46. https:// doi.org/10.1016/j.apcata.2006.07.029.

23. Sharma A, Chakraborty M, Thangavel R. Enhanced Photoelectrochemical Performance of Hydrothermally Grown Tetravalent Impurity (Si4+) Doped Zinc Oxide Nanostructures for Solar Water Splitting Applications. J. Mater. Sci. Mater. Electron. 2018;29(17):14710-14722. https://doi.org/10.1007/ s10854-018-9608-9.
24. Sahoo P, Sharma A, Padhan S, Udayabhanu G, Thangavel R. UV-Assisted Water Splitting of Stable Cl-Doped ZnO Nanorod Photoanodes Grown via Facile Sol-Gel Hydrothermal Technique for Enhanced Solar Energy Harvesting Applications. Sol. Energy 2019;193:148-163. https://doi.org/10.1016/j.solener.2019.09.045.

25. Shao GN, Jeon SJ, Haider MS, Abbass N, Kim HT. Investigation of the Influence of Vanadium, Iron and Nickel Dopants on the Morphology, and Crystal Structure and Photocatalytic Properties of Titanium Dioxide Based Nanopowders. J. Colloid. Interface. Sci. 2016;474:179-189. https://doi.org/10.1016/j.jcis. 2016.04.024.

26. Zhou X, Wang L, Liu X, Xu M, Liu X. Organic/Inorganic Hybrid Consisting of Supportive Poly(Arylene Ether Nitrile) Microspheres and Photocatalytic Titanium Dioxide Nanoparticles for the Adsorption and Photocatalysis of Methylene Blue. Compos. Part B Eng .2019;177:107414. https://doi.org/10.1016/j.compositesb. 2019.107414.

27. Fan J, Liu E, Tian L, Hu X, He Q, Sun T. Synergistic Effect of $\mathrm{N}$ and $\mathrm{Ni}^{2+}$ on Nanotitania in Photocatalytic Reduction of CO2. J. Environ. Eng. 2011;137(3):171-176. https://doi.org/10. 1061/(asce)ee.1943-7870.0000311.

28. She H, Zhou H, Li L, Wang L, Huang J, Wang Q. Nickel-Doped Excess Oxygen Defect Titanium Dioxide for Efficient Selective Photocatalytic Oxidation of Benzyl Alcohol. ACS Sustain. Chem. Eng. 2018;6(9):11939-11948. https://doi.org/10.1021/ acssuschemeng.8b02217.

29. Yoshinaga M, Yamamoto K, Sato N, Aoki K, Morikawa T, Muramatsu A. Remarkably Enhanced Photocatalytic Activity by Nickel Nanoparticle Deposition on Sulfur-Doped Titanium Dioxide Thin Film. Appl. Catal. B Environ. 2009;87:239-244. https://doi.org/10.1016/j.apcatb.2008.08.023.

30. Wang Y, Zhang L, Li S, Jena P. Polyol-Mediated Synthesis of Ultrafine TiO 2 Nanocrystals and Tailored Physiochemical Properties by Ni Doping. J. Phys. Chem. C 2009;113(21):92109217. https://doi.org/10.1021/jp902306h.

31. Li J, Zeng HC. Hollowing Sn-Doped TiO2nanospheres via Ostwald Ripening. J. Am. Chem. Soc. 2007;129(51):1583915847. https://doi.org/10.1021/ja073521w.

32. Nagaveni K, Hegde MS, Ravishankar N, Subbanna GN, Madras G. Synthesis and Structure of Nanocrystalline TiO2 with Lower Band Gap Showing High Photocatalytic Activity. Langmuir 2004;20(7):2900-2907. https://doi.org/10.1021/la035777v.

33. Randeniya LK, Bendavid A, Martin PJ, Preston EW. Photoelectrochemical and Structural Properties of $\mathrm{TiO}_{2}$ and $\mathrm{N}$-Doped $\mathrm{TiO}_{2}$ Thin Films Synthesized Using Pulsed Direct Current Plasma-Activated Chemical Vapor Deposition. J. Phys. Chem. 2007;111(49):18334-18340. https://doi.org/10.1021/ jp075938u.

34. Pelaez M, Nolan NT, Pillai SC, et al. A Review on the Visible Light Active Titanium Dioxide Photocatalysts for Environmental Applications. Appl. Catal. B Environ. 2012;125:331-349. https://doi.org/10.1016/j.apcatb.2012.05.036.

35. Singla P, Pandey OP, Singh K. Study of photocatalytic degradation of environmentally harmful phthalate esters using Ni-doped $\mathrm{TiO}_{2}$ nanoparticles. Int. J. Environ. Sci. Technol. 2016;13(3):849856. https://doi.org/10.1007/s13762-015-0909-8.

36. Sun B, Zhou W, Li H, et al. Synthesis of Particulate Hierarchical 
Tandem Heterojunctions toward Optimized Photocatalytic Hydrogen Production. Adv. Mater. 2018;30(43):1-8. https://doi.org/10.1002/adma.201804282.

37. Zhang W, Gong Y, Mellott NP, Liu D, Li J. Synthesis of Nickel Doped Anatase Titanate as High Performance Anode Materials for Lithium Ion Batteries. J. Power Sources 2015;276:39-45. https://doi.org/10.1016/j.jpowsour.2014.11.098.

38. Sonal S, Singh A, Mishra BK. Decolorization of Reactive Dye Remazol Brilliant Blue R by Zirconium Oxychloride as a Novel Coagulant: Optimization through Response Surface Methodology. Water Sci. Technol. 2018;78(2):379-389. https://doi.org/10.2166/ wst.2018.307.

39. Hanaor DAH, Sorrell CC. Review of the Anatase to Rutile Phase Transformation. J. Mater. Sci. 2011;46(4):855-874. https://doi.org/10.1007/s10853-010-5113-0.

40. Lawin AE, Niyongendako M, Manirakiza C. Solar Irradiance and Temperature Variability and Projected Trends Analysis in Burundi. Climate 2019;7(6):1-20. https://doi.org/10.3390/ CLI7060083.41.

41. He D, Su H, Li X, et al. Heterostructure TiO2 Polymorphs Design and Structure Adjustment for Photocatalysis. Sci. Bull. 2018;63(5):314-321. https://doi.org/10.1016/j.scib.2018.02.008.

42. Sarkar S, Bhattacharjee C, Curcio S. Studies on Adsorption, Reaction Mechanisms and Kinetics for Photocatalytic Degradation of CHD, a Pharmaceutical Waste. Ecotoxicol.
Environ. Saf. 2015;121:154-163. https://doi.org/10.1016/j.ecoenv. 2015.04.036.

43. Etacheri V, Roshan R, Kumar V. Mg-Doped ZnO Nanoparticles for Efficient Sunlight-Driven Photocatalysis. ACS Appl. Mater. Interfaces 2012;4(5):2717-2725. https://doi.org/10.1021/am3003 $59 \mathrm{~h}$

44. Rizzo L, Meric S, Guida M, Kassinos D, Belgiorno V. Heterogenous Photocatalytic Degradation Kinetics and Detoxification of an Urban Wastewater Treatment Plant Effluent Contaminated with Pharmaceuticals. Water Res. 2009;43(16): 4070-4078. https://doi.org/10.1016/j.watres.2009.06.046.

45. Ha Y, Cheung AP. New Stability-Indicating High Performance Liquid Chromatography Assay and Proposed Hydrolytic Pathways of Chlorhexidine. J. Pharm. Biomed. Anal. 1996;14(810):1327-1334. https://doi.org/10.1016/S0731-7085(96)01763-3.

46. Purdy KR. University of Bath. In: Palgrave Macmillan, Macmillan Publishers Ltd., eds. The Grants Register 2021. London: Palgrave Macmillan; 1987. p. 897-898. https://doi. org/10.1057/978-1-349-95988-4_903.

47. Alam U, Khan A, Bahnemann D, Muneer M. Synthesis of Co Doped ZnWO4 for Simultaneous Oxidation of $\mathrm{RhB}$ and Reduction of $\mathrm{Cr}(\mathrm{VI})$ under UV-Light Irradiation. J. Environ. Chem. Eng. 2018;6(4):4885-4898. https://doi.org/10.1016/j.jece. 2018.07.028. 